\title{
Early responses of insulin signaling to high-carbohydrate and high-fat overfeeding
}

\author{
Rebecca L Adochio 1,2, J Wayne Leitner ${ }^{2}$, Karen Gray¹, Boris Draznin ${ }^{1,2}$ and \\ Marc-Andre Cornier*1
}

\author{
Address: ${ }^{1}$ Department of Medicine, University of Colorado Denver, Aurora, Colorado, USA and ${ }^{2}$ Research Service, Department of Veterans Affairs, \\ Denver, Colorado, USA \\ Email: Rebecca L Adochio - rebecca.adochio@ucdenver.edu; J Wayne Leitner - Wayne.Leitner@VA.gov; \\ Karen Gray - Karen.Gray@UCDenver.edu; Boris Draznin - Boris.Draznin@UCDenver.edu; Marc-Andre Cornier* - Marc.Cornier@UCDenver.edu \\ * Corresponding author
}

Published: 28 September 2009

Nutrition \& Metabolism 2009, 6:37 doi:10.1 186/1743-7075-6-37

This article is available from: http://www.nutritionandmetabolism.com/content/6/1/37

(C) 2009 Adochio et al; licensee BioMed Central Ltd.

This is an Open Access article distributed under the terms of the Creative Commons Attribution License (http://creativecommons.org/licenses/by/2.0),

which permits unrestricted use, distribution, and reproduction in any medium, provided the original work is properly cited.
Received: 30 June 2009

Accepted: 28 September 2009

\begin{abstract}
Background: Early molecular changes of nutritionally-induced insulin resistance are still enigmatic. It is also unclear if acute overnutrition alone can alter insulin signaling in humans or if the macronutrient composition of the diet can modulate such effects.

Methods: To investigate the molecular correlates of metabolic adaptation to either highcarbohydrate $(\mathrm{HC})$ or high-fat (HF) overfeeding, we conducted overfeeding studies in 21 healthy lean $(\mathrm{BMI}<25)$ individuals ( 10 women, II men), age 20-45, with normal glucose metabolism and no family history of diabetes. Subjects were studied first following a 5-day eucaloric (EC) diet (30\% fat, $50 \% \mathrm{CHO}, 20 \%$ protein) and then in a counter balanced manner after 5 days of $40 \%$ overfeeding of both a HC $(20 \%$ fat, $60 \% \mathrm{CHO})$ diet and a $\mathrm{HF}(50 \%$ fat, $30 \% \mathrm{CHO})$ diet. At the end of each diet phase, in vivo insulin sensitivity was assessed using the hyperinsulinemic-euglycemic clamp technique. Ex vivo insulin action was measured from skeletal muscle tissue samples obtained 15 minutes after insulin infusion was initiated.
\end{abstract}

Results: Overall there was no change in whole-body insulin sensitivity as measured by glucose disposal rate (GDR, EC: I2.I \pm 4.7 ; HC: $10.9 \pm 2.7$; HF: $10.8 \pm 3.4$ ). Assessment of skeletal muscle insulin signaling demonstrated increased tyrosine phosphorylation of IRS-I $(\mathrm{P}<0.00 \mathrm{I})$ and increased IRS-I-associated phosphatidylinositol 3 (PI 3)-kinase activity $(p<0.00 \mathrm{I})$ following HC overfeeding. In contrast, HF overfeeding increased skeletal muscle serine phosophorylation of IRS$\mathrm{I}(\mathrm{p}<0.00 \mathrm{I})$ and increased total expression of $\mathrm{p} 85 \alpha(\mathrm{P}<0.00 \mathrm{I})$.

Conclusion: We conclude that acute bouts of overnutrition lead to changes at the cellular level before whole-body insulin sensitivity is altered. On a signaling level, HC overfeeding resulted in changes compatible with increased insulin sensitivity. In contrast, molecular changes in HF overfeeding were compatible with a reduced insulin sensitivity. 


\section{Background}

Overnutrition associated with weight gain can lead to obesity and insulin resistance [1-6]. Eventually individuals can develop type 2 diabetes mellitus (T2DM) and cardiovascular disease leading to a significant increase in morbidity and mortality. We aimed to unravel the earliest molecular changes associated with the development of insulin resistance as a result of overnutrition and to determine if acute bouts of caloric excess, before weight gain occurs, can lead to changes in insulin signaling.

There is a paucity of literature studying short-term overfeeding of normal lean individuals. Animal studies have shown that overfeeding can induce insulin resistance acutely [7]. Human studies have shown that varying amounts and duration of overfeeding can lead to elevations in fasting insulin levels in the setting of normoglycemia [8-14]. Our group has previously found that 3 days of overfeeding (50\% caloric excess) in lean healthy individuals led to a significant decrease in whole-body insulin sensitivity $[15,16]$. Most recently, Brøns, et al. found that 5 days of high-fat overfeeding (50\% caloric excess) in lean individuals resulted in no change in whole-body insulin sensitivity as measured by M-value and Glucose Disposal Rate (GDR) [17]. Therefore, it remains unclear if acute overnutrition alone can induce insulin resistance in humans. If acute overfeeding can impact insulin sensitivity, the next question is whether the effect is altered by the macronutrient content of the consumed diet. Although many studies in the literature have assessed macronutrient effects on insulin sensitivity [18-22] these studies were not performed in the setting of overfeeding. Population studies have shown that diets rich in fat appear to be associated with development of insulin resistance, obesity and T2DM $[23,24]$. There have also been reports that diets rich in carbohydrates with a high glycemic index may be associated with increased hepatic glucose production and the development of T2DM $[25,26]$.

The potential link between energy intake and changes in insulin action remain unclear. At a whole body level, insulin resistance can be defined when higher than normal concentrations of insulin are necessary to maintain euglycemia. On a cellular level, metabolic insulin resistance is known to display a reduced strength of signaling via the insulin receptor substrate (IRS)-phophatidylinositol (PI) 3-kinase pathway. In almost all cases of insulin resistance there is a decline in PI 3-kinase activity [27-29]. Two complementary mechanisms have emerged as potential explanations for the reduced strength of the IRS-PI 3-kinase signaling pathway. First, PI 3-kinase activity is minimized secondary to serine phosphorylation of IRS proteins by intracellular signaling intermediates such as mTOR-p70 S6 (S6K1) kinase-dependent mechanism or other kinases (JNK, IKK $\beta$, or PKC). Serine phosphorylation of IRS pro- teins results in a diminished ability of IRS proteins to attract PI 3-kinase [30-37]. In response to insulin and amino acids mammalian target of rapamycin (mTOR), a serine/threonine kinase, phosphorylates and modulates activity of S6K1 kinase [38-40]. The insulin activation of mTOR and S6K1 kinase works through the IRS-1/PI 3kinase/Akt pathway, while amino acids seem to exert a direct effect on mTOR $[41,42]$. Activation of mTOR and S6K1 kinase leads to serine phosphorylation of IRS-1, with a subsequent decline in tyrosine phosphorylation of IRS-1 and IRS-1-associated PI 3-kinase activity, as discussed above. Although many mechanisms leading to serine phosphorylation of IRS proteins have been explored, the nutritional effect on this process in humans is not completely understood.

Second, a disruption in the balance between the amounts of the PI 3-kinase subunits may play a role in the development of insulin resistance $[43,44]$. This enzyme consists of a regulatory subunit, p85, and a catalytic subunit, p110 [45]. Normally, p85 monomer exists in excess to p110. Since the p85 subunit of PI 3-kinase directly binds to IRS1 , there exists a competition between the free p85 monomer and the p85-p110 heterodimer for the binding site on IRS-1. Since only the heterodimer is responsible for PI 3kinase activity, increases or decreases in p85 expression could lead to increased or decreased PI 3-kinase activity in an inverse manner [46-49]. We have previously demonstrated that in the women who displayed reduced wholebody insulin sensitivity following 3 days of $50 \%$ overfeeding there was an increase in total p85 $\alpha$ (the most abundant isoform of p85) expression in skeletal muscle. This increase in p85 $\alpha$ expression was inversely correlated with PI 3-kinase activity [16].

We thus hypothesized that acute bouts of overnutrition would alter skeletal muscle insulin signaling prior to seeing changes in whole body insulin sensitivity. Moreover, we hypothesized that high fat overnutrition would result in greater impairment in insulin signaling than high carbohydrate overnutrition. The present study was designed to examine these hypotheses.

\section{Methods \\ Subjects}

Twenty-one lean (BMI $21.8 \pm 1.8)$, healthy men $(\mathrm{n}=11)$ and women $(\mathrm{n}=10)$ with normal glucose tolerance (as determined by oral glucose tolerance testing) completed the study (Table 1). The study was approved by the Colorado Multiple Institutional Review Board, and all subjects gave informed consent.

\section{Materials}

Bovine serum albumin (BSA) and protease inhibitors aprotinin and leupeptin were purchased from Boehringer 
Table I: Baseline characteristics

\begin{tabular}{lc}
\hline Characteristic & Value \\
\hline $\mathrm{N}(\mathrm{M} / \mathrm{W})$ & $21(\mathrm{Il} / \mathrm{l} 0)$ \\
Age (years) & $27.8 \pm 0.9$ \\
Weight $(\mathrm{kg})$ & $66.6 \pm 1.5$ \\
BMI $\left(\mathrm{kg} / \mathrm{m}^{2}\right)$ & $21.8 \pm 0.4$ \\
Waist Circumference $(\mathrm{cm})$ & $78.7 \pm 1.7$ \\
Fat Free Mass $(\mathrm{kg})$ & $51.0 \pm 2.1$ \\
Percent Body Fat $(\%)$ & $21.9 \pm 1.9$ \\
\hline
\end{tabular}

Mean \pm SD

Mannheim (Indianapolis, IN, USA). Antibodies to IRS-1, and $\mathrm{p} 85 \alpha$ were purchased from Upstate Biotechnology (Lake Placid, NY, USA). Antibodies to p110 were purchased from Santa Cruz Biotechnology (Santa Cruz, CA, USA). Anti-phosphoserine IRS-1 antibody was from Upstate Biotechnology, pY-20 antibody was from BD Transduction Laboratories (San Diego, CA, USA). Antibodies to mTOR, phospho-mTOR, p70S6 kinase (S6K1) and phospho-p70S6 kinase (Thr 3389 and Thr421/ Ser424) were from Cell Signaling Technology (Danvers, MA, USA). Secondary horseradish-peroxidase-conjugated antibody, protein A Sepharose and chemeluminescence detection reagent, ECLplus Western Blotting Analysis System, and ImageQuant TL software from GE Healthcare Bio Science/Amersham Biosciences, Piscataway, NJ. $\gamma^{32} \mathrm{P}-$ ATP was purchased from Perkins-Elmer (Boston, MA). Whatman flexible plates for thin layer chromatography were obtained from Fisher Scientific (Denver, CO). Analytical grade resins, polyvinylidene difluoride membranes, PAGE gel equipment and protein assay kits were from Bio-Rad Laboratories (Hercules, CA, USA).

\section{Study Design}

Subjects first underwent baseline assessments of resting metabolic rate (RMR) using the SensorMedics Vmax Spectra 29 metabolic cart (Sensormedics, Yorba Linda, CA) and body composition determined by dual x-ray absorptiometry (DEXA) using Hologic Discovery version 12.6. Subjects were then studied on three separate occasions with a one month wash-out between study visits. The first study day served as a baseline and was performed after subjects were fed a eucaloric diet (30\% fat, 50\% carbohydrate, $20 \%$ protein) for 5 days. Estimates of daily energy needs were made using several factors: 1) the Harris-Benedict equation, 2) baseline RMR plus an activity factor, and 3) lean body mass. Subjects were then studied after 5 days of high-carbohydrate (HC; $20 \%$ fat, 60\% carbohydrate, $20 \%$ protein) and 5 days of high-fat (HF; 50\% fat, $30 \%$ carbohydrate, $20 \%$ protein) overfeeding (40\% caloric excess over a eucaloric diet) in a cross-over counter-balanced manner. Because the two hypercaloric diets contained $40 \%$ excess calories, carbohydrate intake on the
HF diet and fat intake on the HC diet were similar to amounts consumed during eucaloric feeding (example: eucaloric $2000 \mathrm{kCal}$ diet contained $66.7 \mathrm{~g}$ fat, $250 \mathrm{~g} \mathrm{CHO}$ and $100 \mathrm{~g}$ protein; HC $2800 \mathrm{kCal}$ diet contained $62.2 \mathrm{~g}$ fat, $420 \mathrm{~g}$ CHO and $140 \mathrm{~g}$ protein; HF $2800 \mathrm{kCal}$ diet contained $155.6 \mathrm{~g}$ fat, $210 \mathrm{~g} \mathrm{CHO}$ and $140 \mathrm{~g}$ protein). Dietary lipid for all diets contained a 1:1:1 ratio of monounsaturated, polyunsaturated and saturated fats. Food for all study diets (eucaloric, HC and HF) was provided by the Clinical and Translational Research Center (CTRC) kitchen. Subjects selected food choices from the CTRC kitchen menu (Additional File 1). The HC diet was enriched in fruits and starches. The HF diet was enriched in dairy, nuts, and oils. Subjects presented to the CTRC every morning to pick up food and be weighed. Subjects were asked to maintain their usual level of activity throughout the study. They were also asked not to consume any alcoholic or calorie-containing beverages.

\section{Study Days}

Subjects were admitted to the inpatient CTRC the night of day 5 for each of the three diet phases for an overnight fast. The next morning a euglycemic-hyperinsulinemic clamp and skeletal muscle biopsy were performed. An antecubital venous catheter was placed in one arm for infusions, and another catheter was placed retrograde in a dorsal hand vein of the contralateral arm for sampling, using the heated hand technique to obtain arterialized venous blood. Glucose production and disposal were measured using a euglycemic-hyperinsulinemic clamp. After baseline blood samples were taken a primed (19 $\mu \mathrm{mol} / \mathrm{kg})$, constant $(0.22 \mu \mathrm{mol} / \mathrm{kg} / \mathrm{min})$ infusion of [6,6${ }^{2} \mathrm{H}_{2}$ ] glucose was started to measure glucose disposal rate. A primed, continuous infusion of insulin at $40 \mathrm{mU} / \mathrm{m}^{2} /$ min was then initiated and continued from time 120 to 240 minutes. Blood samples were taken at 90, 100, 110, 220, 230, and $240 \mathrm{~min}$ for steady state measurements of metabolites and isotope enrichments. Blood samples were taken every 5 minutes during the insulin infusion for bedside glucose analysis, and a $20 \%$ dextrose solution enriched with $\left[6,6-{ }^{2} \mathrm{H}_{2}\right]$ glucose was infused and adjusted to maintain euglycemia at a blood glucose level of approximately $90 \mathrm{mg} / \mathrm{dl}$. Rates of glucose appearance (Ra) and disappearance $(\mathrm{Rd})$ were calculated using the modified Steele equation $[50,51]$. The skeletal muscle biopsy was performed once the insulin prime was complete (after 15 minutes) in order to assess insulin-stimulated effects on PI 3-kinase activity. Subcutaneous tissue overlying the vastus lateralis muscle was infiltrated with $1 \%$ lidocaine. A small incision was made with a scalpel down through the level of the fascia. A Bergstrom sidecut biopsy needle with suction was used to remove approximately $0.25 \mathrm{~g}$ of skeletal muscle tissue. Tissue samples were frozen immediately using the "freeze clamp" method. The biopsy samples were stored at $-80^{\circ} \mathrm{C}$ until used. 


\section{Determination of intramyocellular lipid content (IMCL)} In a subset of subjects $(\mathrm{N}=10)$, intramuscular triglyceride content of the soleus muscle was measured via ${ }^{1} \mathrm{H}$ (proton) magnetic resonance spectroscopy (MRS) performed using the 3.0 T whole-body MRI scanner (GE Medical Systems, Waukesha, WI). The spectroscopic acquisition is performed using the probe-p (PRESS) pulse sequence with parameters $(\mathrm{TR} / \mathrm{TE}=2000 / 100 \mathrm{~ms}, 128$ averages, total acquisition time 7 minutes) optimized to avoid signals from fat. The resulting spectra are analyzed using LCModel software which fits the spectra using basis sets consisting of solution metabolite spectra.

\section{Clinical Laboratory Measurements}

Plasma glucose level was measured throughout the euglycemic-hyperinsulinemic clamp studies at the bedside every 5 minutes using a YSI glucose analyzer (YSI Inc, Yellow Springs, $\mathrm{OH}$ ). Baseline and steady-state analysis included blood sampling for insulin, glucose, free fatty acids (FFAs), glycerol, triglycerides, leptin, adiponectin, TNF- $\alpha$ and interleukin (IL)-6. Insulin was determined by radioimmunoassay (Diagnostic Systems Laboratory, Webster, TX). Serum glucose levels were determined using hexokinase, UV and triglycerides were determined by enzymatic assay (Olympus America, Inc., Center Valley, PA). FFAs were determined using an enzymatic assay (WaKo Chemicals, Richmond, VA). Glycerol was determined using an enzymatic assay (R-Biopharmm Inc., Marshall, MI). Leptin and adiponectin levels were determined by radioimmunoassays (Linco Research, Inc., St. Charles, MO). TNF- $\alpha$ and IL- 6 were determined by ELISA (R\&D Systems, Minneapolis, MN). Glucose isotopic enrichment was measured by gas chromatography/mass spectrometry (Metabolic Solutions, Inc., Nashua, NH).

\section{Western Blot Analysis}

Immunoprecipitated IRS-1 was immunoblotted with pY20 and anti-serine 307 IRS- 1 antibodies to determine extent of tyrosine and serine phosphorylation of IRS-1 as well as with anti-IRS-1 antibody for assessment of total IRS-1. Immunoprecipitated IRS-1 was also immunoblotted with p110 antibodies to determine the total amount of IRS-1-associated p110 expression. Tissue homogenates were immunoprecipitated and immunoblotted with p $85 \alpha$ specific antibody for assessment of p $85 \alpha$ protein expression. Finally, homogenates were also immunoprecipitated with mTOR and S6K1 specific antibodies and then blotted with phospho-mTOR (serine 2448) and phospho-S6K1 kinase (serine 371) antibodies, respectively. The total amounts of mTOR and S6k1 kinase were determined by immunoblotting with corresponding specific antibodies.

\section{Determination of IRS- I-associated PI 3-kinase activity} Lysates prepared from the tissue biopsy were immunoprecipitated with IRS-1 antibody. PI 3-kinase activity is deter- mined in 1 to $3 \mu \mathrm{L}$ of the immunoprecipitate by the thin layer chromatography as described in several of our publications [52].

\section{Statistical Analysis}

Data are presented as mean \pm SEM. Statistical analysis were done using SigmaStat software (Jandel Scientific, San Rafael, CA, USA). The effects of study diets were analyzed using repeated measures analysis of variance (ANOVA). $p$ values of $<0.05$ were considered statistically significant. No gender differences were found, so all results reported include data from men and women combined as one cohort.

\section{Results \\ In Vivo}

After 5 days of eucaloric (EC) feeding, baseline wholebody insulin sensitivity and hepatic glucose production were determined by euglycemic-hyperinsulinemic clamp. Subjects were then studied after 5 days of high-carbohydrate (HC) and high-fat (HF) overfeeding in a counter balanced manner. There was no difference in weight between study days (EC: $66.6 \pm 1.6 \mathrm{~kg}$; HC: $67.5 \pm 1.5 \mathrm{~kg}$, HF: $67.2 \pm 1.6 \mathrm{~kg}, \mathrm{p}=0.92)$. HC overfeeding resulted in increased fasting insulin and triglyceride concentrations and lower fasting free fatty acid concentrations as compared to EC feeding (Table 2). HF overfeeding was associated with a significant decrease in triglyceride concentrations compared to EC and HC feedings (Table 2).

Interestingly, five days of $\mathrm{HC}$ or HF overfeeding did not alter whole-body insulin sensitivity compared to eucaloric feeding, expressed as either M-Value or GDR (Table 3). Steady-state serum glucose and insulin levels were equivalent at the end of the euglycemic-hyperinsulinemic clamp for all three study days (Table 3). There was also no significant change in basal hepatic glucose output following either overfeeding diet (Table 3).

Table 2: Fasting metabolic data

\begin{tabular}{lccc}
\hline & EC & HC & HF \\
\hline Insulin $(\mathrm{mU} / \mathrm{mL})$ & $4.2 \pm 0.4$ & $5.8 \pm 0.6^{*}$ & $4.4 \pm 0.4$ \\
Glucose $(\mathrm{mg} / \mathrm{dL})$ & $84.2 \pm 1.3$ & $85.5 \pm 1.7$ & $84.9 \pm 1.4$ \\
FFA $(\mu \mathrm{Eq} / \mathrm{L})$ & $447 \pm 41$ & $315 \pm 32.5^{*}$ & $404 \pm 25.3$ \\
Triglycerides $(\mathrm{mg} / \mathrm{dL})$ & $69.1 \pm 5.9$ & $91.0 \pm 11.0^{* *}$ & $60.6 \pm 7.9 \#$ \\
Glycerol $(\mu \mathrm{M} / \mathrm{L})$ & $72.1 \pm 7.8$ & $73.2 \pm 11.4$ & $69.6 \pm 8.9$ \\
Adiponectin $(\mu g / \mathrm{mL})$ & $10.0 \pm 1.2$ & $9.9 \pm 1.1$ & $9.5 \pm 1.2$ \\
Leptin $(\mathrm{ng} / \mathrm{mL})$ & $6.2 \pm 1.6$ & $8.3 \pm 2.1$ & $6.5 \pm 1.5$ \\
TNF- $\alpha(\mathrm{pg} / \mathrm{mL})$ & $2.1 \pm 0.4$ & $2.2 \pm 0.5$ & $2.0 \pm 0.4$ \\
Interleukin-6 $(\mathrm{pg} / \mathrm{mL})$ & $0.9 \pm 0.1$ & $0.9 \pm 0.1$ & $1.3 \pm 0.5$ \\
\hline
\end{tabular}

Mean \pm SE.

$\mathrm{EC}=$ eucaloric diet, $\mathrm{HC}=$ high-carbohydrate overfeeding, $\mathrm{HF}=$ highfat overfeeding

$*_{p}<0.03$ compared to EC, ${ }^{*} *_{p}<0.00$ I compared to EC, \#p $<0.00$ I compared to $\mathrm{HC}$ 
Table 3: Euglycemic-hyperinsulinemic clamp data

\begin{tabular}{lccc}
\hline & EC & HC & HF \\
\hline M-Value (mg/kg FFM-min) & $11.4 \pm 2.7$ & $11.2 \pm 2.9$ & $11.1 \pm 2.1$ \\
GDR (mg/kg FFM-min) & $12.1 \pm 4.7$ & $10.9 \pm 2.7$ & $10.8 \pm 3.4$ \\
Steady State Glucose (mg/dL) & $79.2 \pm 5.1$ & $81.8 \pm 8.7$ & $79.6 \pm 8.8$ \\
Steady State Insulin (mU/mL) & $66.8 \pm 22.3$ & $60.2 \pm 17.4$ & $59 \pm 27.1$ \\
MCR (mL/m²-min) & $719 \pm 263.5$ & $785 \pm 175.2$ & $825 \pm 232.6$ \\
Rest HGO (mg/kg FFM-min) & $3.39 \pm 0.5$ & $3.79 \pm 1.5$ & $3.42 \pm 1.0$ \\
\hline
\end{tabular}

Mean \pm SE.

$\mathrm{EC}=$ eucaloric diet, $\mathrm{HC}=$ high-carbohydrate overfeeding, $\mathrm{HF}=$ high-fat overfeeding

GDR = glucose disposal rate, $\mathrm{MCR}=$ metabolic clearance rate of insulin, $\mathrm{HGO}=$ hepatic glucose output

Measurements of serum adipokines and markers of systemic inflammation revealed no significant change in serum adiponectin or leptin levels following overfeeding with either HC or HF diets. Similarly, there was no significant change in TNF $\alpha$ or interleukin-6 levels following either overfeeding diet (Table 2).

Finally, assessment of intramyocellular triglyceride content (IMCL) performed in a subset of subjects $(\mathrm{N}=10)$ following both HC and HF overfeeding demonstrated 17 $22 \%$ increases in IMCL accumulation after both diets (EC: $1077.0 \pm 103.2$, HC: $1323.3 \pm 137.6 p=0.0025$, HF: $1268.8 \pm 128.9 p=0.0136)$.

\section{Ex Vivo}

We then examined ex vivo markers of insulin signaling in skeletal muscle of individuals enrolled into this study. All biopsies were obtained at the end of each feeding period in the insulin-stimulated condition. Five days of HC overfeeding resulted in significant increases in tyrosine phosphorylation of IRS-1 (Figure 1A), with no change in total IRS-1 protein expression compared to EC feeding (Figure 2). In contrast, HF overfeeding resulted in increased serine phosphorylation of IRS-1 (Figure 1B) with no change in the amount of total IRS-1 (Figure 2). Representative blots of total and phosphorylated IRS-1 are shown in Figure 2 along with all subsequent blots discussed below.

In concert with these changes in IRS-1 phosphorylation, insulin-stimulated IRS-1-associated PI 3-kinase activity increased following HC overfeeding (Figure 3A). PI 3kinase is a heterodimer comprised of regulatory, p85, and catalytic, p110, subunits. While p85 is responsible for association of PI 3-kinase with IRS-1, it is actually association of p110 with IRS-1 that determines PI 3-kinase activity. Therefore, we examined association of p110 with IRS1 in response to insulin in patients after 5 days of overfeeding either HC or HF compared to 5 days of eucaloric feeding. The IRS-1 associated p110 was significantly increased following HC overfeeding (Figure 3B), supporting a positive influence of the HC diet on PI 3-kinase activity.
Decreased association of PI 3-kinase with IRS-1 can be a consequence of either serine phosphorylation of IRS- 1 or of an increased expression of p 85 monomer that competes with p85-p110 heterodimer for the IRS-1 binding sites. Therefore, we examined total amounts of p85a (a predominant isomer of p85) after overfeeding HC and HF. Total $\mathrm{p} 85 \alpha$ protein expression was increased following HF overfeeding compared to eucaloric feeding leading to enhanced competition with PI 3-kinase heterodimer, thus contributing to the reduction in IRS- 1 associated p110 levels (Figure 3C). In contrast, p85a levels were lower following HC overfeeding compared to HF over-

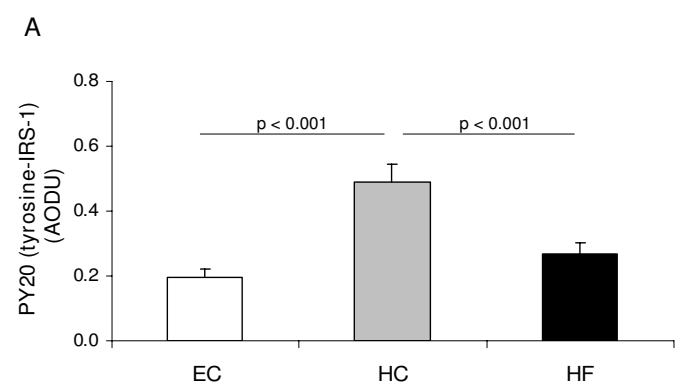

B

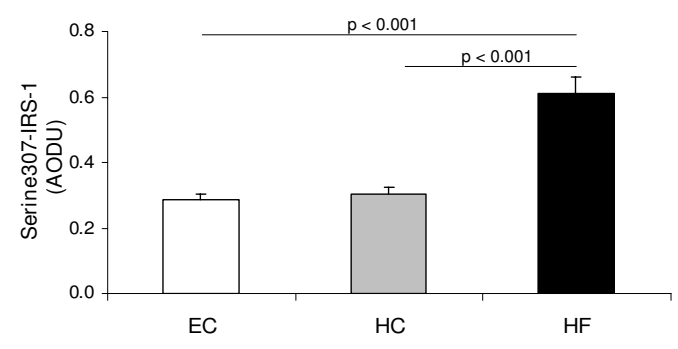

Figure I

Phosphorylation of IRS-I. Tyrosine (A) and Serine (B) phosphorylation of IRS-I in skeletal muscle following Eucaloric feeding (EC), high-carbohydrate overfeeding (HC), and high-fat overfeeding (HF). HC overfeeding increased tyrosine phosphorylation of IRS-I compared to EC feeding. HF overfeeding increased serine phosphorylation of IRS-I compared to EC feeding. 


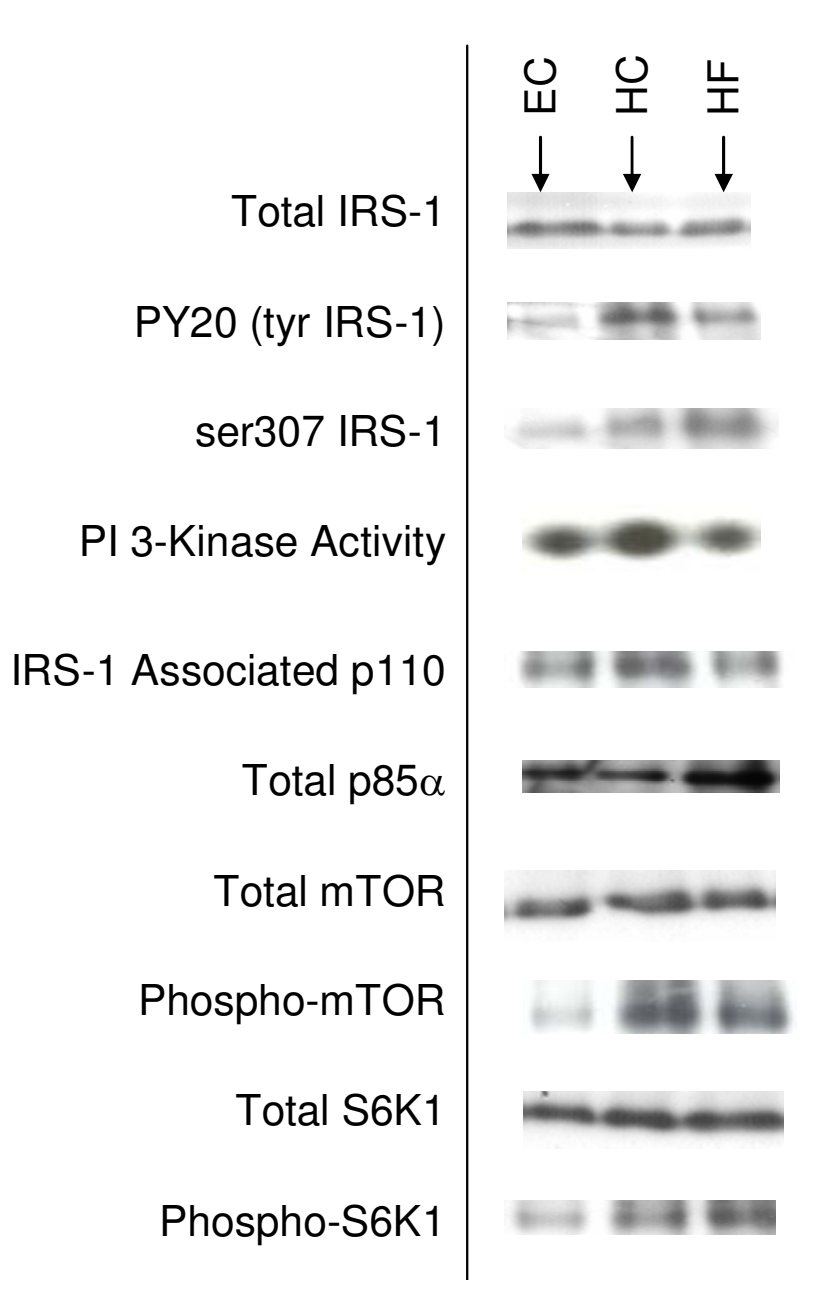

Figure 2

Representative blots. Representative blots from ex vivo skeletal muscle tissue following Eucaloric feeding (EC), highcarbohydrate overfeeding (HC), and high-fat overfeeding (HF).

feeding, thus maintaining minimal competition with PI 3-kinase for the IRS-1 binding sites (Figure 3C).

Looking further downstream from PI 3-kinase, we assessed changes in the nutrient sensor, mTOR, and its effect on S6K1 kinase. Total protein expression of mTOR and S6K1 kinase was unchanged following the study diets (Figure 2). However, there was a significant increase in phosphorylated mTOR resulting in increased phosphorylation of S6K1 following both overfeeding diets (Figure 4).

\section{Discussion}

The salient feature of the current study is that short-term overfeeding in healthy lean individuals (40\% caloric excess for 5 days) results in significant changes in skeletal
A
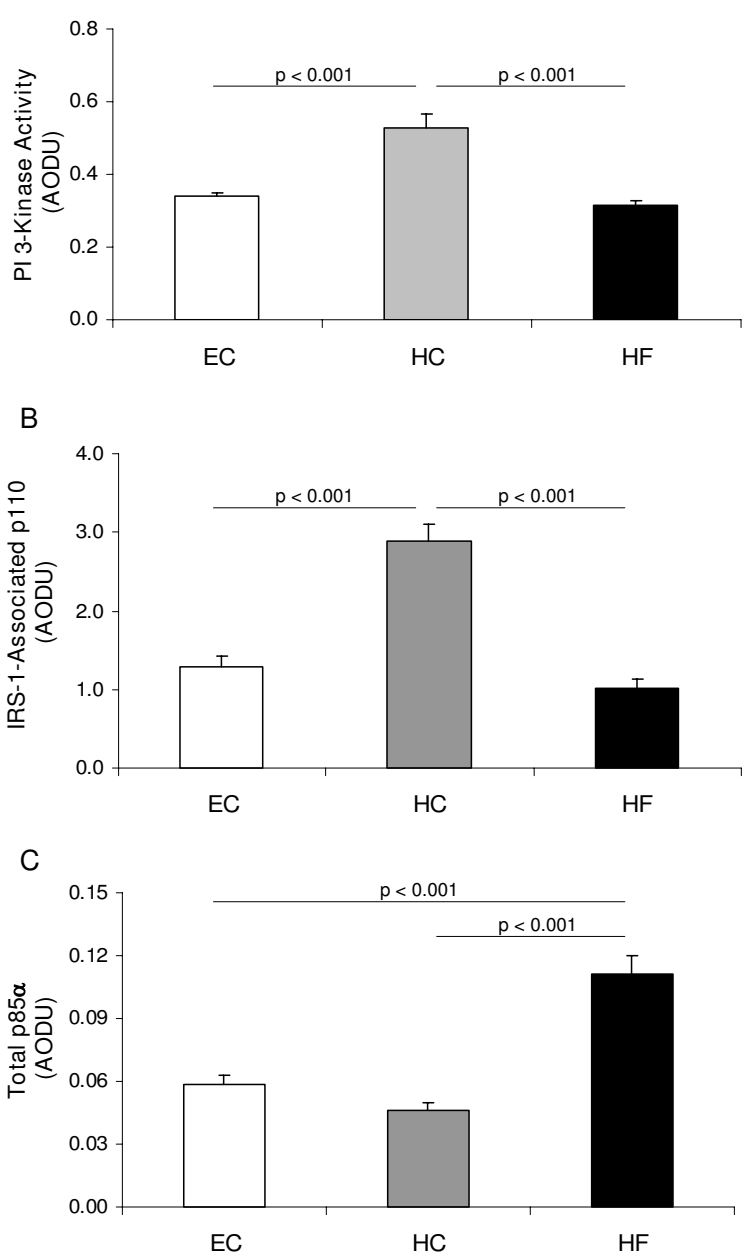

Figure 3

PI 3-kinase activity and subunit expression. IRS-I-associated PI 3-kinase activity (A), IRS-I-associated $\mathrm{pl} I 0$ protein expression (B), and Total p85 $\alpha$ protein expression (C) in skeletal muscle following Eucaloric feeding (EC), high-carbohydrate overfeeding (HC), and high-fat overfeeding (HF). HC overfeeding increased IRS-I associated PI 3-kinase activity and IRS-I associated pI I 0 expression compared to EC feeding. HF overfeeding increased total $p 85 \alpha$ expression compared to EC feeding.

muscle insulin signaling before any alterations in total body insulin sensitivity are evident. Furthermore, macronutrient composition of the overfeeding diet has a profound influence on changes in insulin signaling in skeletal muscle.

We found that consuming a high-carbohydrate (HC) hypercaloric diet results in a significant increase in tyrosine phosphorylation IRS-1, with increased association of p110 (a catalytic subunit of PI 3-kinase) with IRS-1 and 


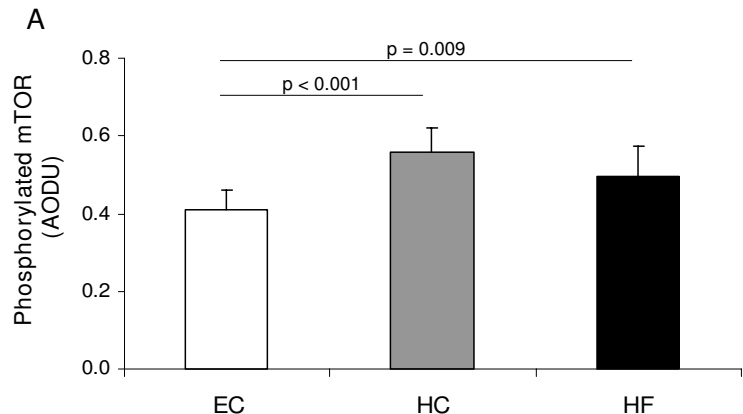

B

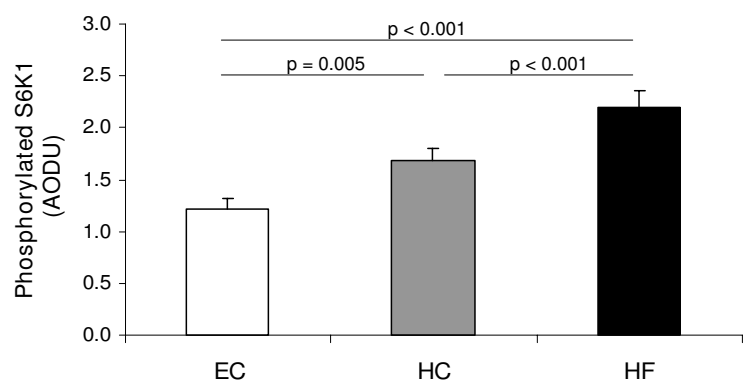

Figure 4

mTOR and S6KI activity. Phosphorylation of mTOR (A) and S6KI (B) in skeletal muscle following Eucaloric feeding (EC), high-carbohydrate overfeeding ( $\mathrm{HC})$, and high-fat overfeeding (HF). Both HC and HF overfeeding increased phosphorylation of mTOR and S6KI compared to EC feeding.

enhanced IRS-1-associated insulin-stimulated PI 3-kinase activity. These changes in insulin signaling usually denote increased insulin sensitivity and may be a result of the modest hyperinsulinemia seen with HC overfeeding. Whole body insulin sensitivity as measured by the euglycemic-hyperinsulinemic clamp, however, did not change after 5 days of overfeeding, suggesting the presence of early changes in insulin signaling in response to a highcarbohydrate load directed at better disposal of this load in order to maintain whole-body insulin sensitivity.

In contrast, we found that high-fat (HF) overfeeding results in a significant increase in serine phosphorylated IRS-1, a traditional determinant of insulin resistance. At the same time, HF overfeeding is associated with increased expression of p85 $\alpha$ and decreased association of p110 with IRS-1 and decreased insulin-stimulated PI 3kinase activity. Although in the present study we cannot determine which component (serine phosphorylation of IRS- 1 or increased expression of $\mathrm{p} 85 \alpha$ ) plays a greater role, these changes are typically associated with insulin resistance in skeletal muscle. In our previous studies, overfeeding healthy female subjects with 50\% caloric excess for 3 days, we also observed an increase in expression of $p 85 \alpha$ before serine phosphorylation of IRS-1 [16], suggesting that excess energy intake may drive overexpression of p $85 \alpha$ as an earliest molecular change in response to overfeeding. As with HC overfeeding, these ex-vivo alterations were not accompanied by any change in the in vivo assessment of insulin sensitivity. Excess fat intake appears to alter carbohydrate induced insulin signaling at the level of skeletal muscle but without an appreciable change in whole body insulin sensitivity. These findings again imply the appearance of early changes to acute bouts of overnutrition; however, the effects vary depending on the macronutrient composition of the diet.

Assessing effects further downstream of PI 3-kinase, we found that both HC and HF overfeeding led to significant increases in activation of the nutrient sensor, mTOR, and its downstream target, S6K1. Ability of S6K1 to promote serine phosphorylation of IRS-1 has been suggested as a potential mechanism of insulin resistance [30-37,53,54]. In this study, both overfeeding diets induced significant increases in phosphorylation of mTOR and S6K1, yet only HF overfeeding was associated with increased serine phosphorylation of IRS-1. Further studies are needed to evaluate this discrepancy.

Interestingly, in a subset of subjects, we found a significant increase in intramyocellular lipid content (IMCL) following both HC and HF overfeeding compared to baseline. This increase was observed regardless of the macronutrient content of the diet. This increase in IMCL was also seen in the setting of unchanged whole-body insulin sensitivity, suggesting that either IMCL is not associated with insulin sensitivity, the duration of the study was not sufficient to see an effect, or the type or source of myocellular lipid may be important. Although literature suggests that increases in intramuscular triglyceride are associated with increased insulin resistance [55-57], some data suggest these may not be related $[58,59]$. Additionally, studies have shown that the source of intramyocellular lipid may determine how the lipid accumulation affects insulin responsiveness. Ceremide and diacylglycerol (DAG) have been linked to deleterious effects on insulin signaling in muscle and DAG levels can increase following intake of a diet high in saturated fat [60,61]. In contrast, triacylglycerol fatty acids (TAG) accumulate in muscle following a diet high in poluyunsaturated fatty acids and can lead to improved insulin sensitivity [61]. Clearly further studies are needed to understand the relationship and interaction between IMCL and insulin signaling. Future studies would be strengthened by performing direct measurements of intramyocellular lipid metabolites.

There are a few limitations to this study that need to be discussed. First, the duration and amount of overfeeding were chosen to be 5 days and $40 \%$, respectively. It is pos- 
sible that a longer duration of overnutrition is necessary to impact whole-body insulin sensitivity. Brøns, et al. recently published data where they also did not see any appreciable difference in whole-body insulin sensitivity, as measured by euglycemic-hyperinsulinemic clamp following 5 days of $50 \%$ caloric excess feeding [17]. Conceivably, changes in the whole-body insulin sensitivity may not be seen either until an individual begins to show clinically significant weight gain or there is a more significant caloric excess. Studies examining longer term overfeeding should be performed to further assess this issue. Second, despite strict eligibility criteria there was significant heterogeneity in baseline measures of insulin sensitivity (Mvalue: 7.68 to $17.71 \mathrm{mg} / \mathrm{kgFFM} / \mathrm{min}$ ). While we did not see an association between baseline insulin sensitivity and responses to overfeeding there may be differences in how individuals can or cannot respond to overnutrition based on their baseline insulin sensitivity. Studies in larger cohorts of subjects might be needed to uncover changes in whole-body insulin sensitivity following overnutrition.

\section{Conclusion}

We conclude that acute bouts of overnutrition lead to early changes at the cellular level before whole-body insulin sensitivity is altered. Our lean healthy cohort of subjects may be metabolically flexible and thus able to adapt to such changes in their diet. High carbohydrate overfeeding induced mild elevations in insulinemia and triglyceridemia, while still suppressing FFA, hepatic glucose production and stimulating glucose disposal. On a signaling level, HC overfeeding induced changes compatible with increased insulin sensitivity. In contrast, molecular changes in HF overfeeding were compatible with a reduced insulin sensitivity, while in vivo insulin sensitivity remained unchanged. More studies are needed to determine when these early responses can no longer sustain normal whole-body insulin sensitivity and which individuals may not be as capable of adapting to overnutrition and why.

\section{Competing interests}

The authors declare that they have no competing interests.

\section{Authors' contributions}

RLA conducted euglycemic-hyperinsulinemic clamps, performed skeletal muscle biopsies, analyzed in vivo data, performed the statistical analysis and drafted the manuscript. JWL performed all ex vivo analysis of skeletal muscle tissue. KG was the study coordinator, organized all subject visits and assisted with euglycemic-hyperinsulinemic clamps. BD co-conceived of the study, and participated in its design and coordination, assisted with data analysis and helped draft the manuscript. MAC co-conceived of the study, and participated in its design and coordination, conducted euglycemic-hyperinsulinemic clamps, performed skeletal muscle biopsies, assisted with data analysis and statistical analysis and helped draft the manuscript. All authors read and approved the final manuscript.

\section{Additional material}

\section{Additional file 1}

Examples of Diets. The data provided represent an example of the types and amounts of foods for each diet for one subject.

Click here for file

[http://www.biomedcentral.com/content/supplementary/1743-

7075-6-37-S1.DOC]

\section{Acknowledgements}

This work was supported by NIH/NCRR Colorado CTSI Grant Number ULI RR025780, NIH/NIDDK Clinical Nutrition Research Unit Grant Number DK48520, NIH/NIDDK Grant Number R56 DK07704 I (to M. Cornier), and The Department of Veterans Affairs Merit Review Award (to B. Draznin)

\section{References}

I. Ferrannini E, Natali A, Bell P, Cavallo-Perin P, Lalic N, Mingrone G: Insulin resistance and hypersecretion in obesity. European Group for the Study of Insulin Resistance (EGIR). J Clin Invest 1997, 100: 1166-1173.

2. Chan JM, Rimm EB, Colditz GA, Stampfer MJ, Willett WC: Obesity, fat distribution, and weight gain as risk factors for clinical diabetes in men. Diabetes Care 1994, 17:961-969.

3. Colditz GA, Willett WC, Rotnitzky A, Manson JE: Weight gain as a risk factor for clinical diabetes mellitus in women. Ann Intern Med 1995, I 22:48I-486.

4. Koh-Banerjee P, Wang Y, Hu FB, Spiegelman D, Willett WC, Rimm $E B$ : Changes in body weight and body fat distribution as risk factors for clinical diabetes in US men. Am J Epidemiol 2004, I59: II50-II59.

5. Olefsky JM, Kolterman OG, Scarlett JA: Insulin action and resistance in obesity and noninsulin-dependent type 2 diabetes mellitus. Am J Physiol 1982, 243:EI5-E30.

6. Lazar MA: How obesity causes diabetes: not a tall tale. Science 2005, 307:373-375.

7. Wang J, Obici S, Morgan K, Barzilai , Feng Z, Rossetti L: Overfeeding rapidly induces leptin and insulin resistance. Diabetes 200I, 50:2786-2791.

8. Horton TJ, Drougas H, Brachey A, Reed GW, Peters JC, Hill JO: Fat and carbohydrate overfeeding in humans: different effects on energy storage. Am J Clin Nutr 1995, 62:19-29.

9. Chinayon S, Goldrick RB: Effects of overfeeding on carbohydrate tolerance, insulin secretion, esterification and lipolysis in healthy subjects. Horm Metab Res 1978, 10:182-186.

10. Clore JN, Helm ST, Blackard WG: Loss of hepatic autoregulation after carbohydrate overfeeding in normal man. J Clin Invest 1995, 96:1967-1972.

II. Kashiwagi A, Mott D, Bogardus C, Lillioja S, Reaven GM, Foley JE: The effects of short-term overfeeding on adipocyte metabolism in Pima Indians. Metabolism 1985, 34:364-370.

12. Kolaczynski JW, Ohannesian JP, Considine RV, Marco CC, Caro JF: Response of leptin to short-term and prolonged overfeeding in humans. J Clin Endocrinol Metab 1996, 81:4162-4165.

13. Oppert JM, Nadeau A, Tremblay A, Després JP, Thériault G, Dériaz $O$, Bouchard C: Plasma glucose, insulin, and glucagon before and after long-term overfeeding in identical twins. Metabolism 1995, 44:96-105.

14. Ravussin E, Schutz Y, Acheson KJ, Dusmet M, Bourquin L, Jéquier E: Short-term, mixed-diet overfeeding in man: no evidence for "luxuskonsumption". Am J Physiol 1998, 249:E470-E477. 
15. Cornier MA, Bergman BC, Bessesen DH: The effects of shortterm overfeeding on insulin action in lean and reducedobese individuals. Metabolism 2006, 55:|207-|2| 4 .

16. Cornier MA, Bessesen DH, Gurevich I, Leitner JW, Draznin B: Nutritional up-regulation of p85a expression is an early molecular manifestation of insulin resistance. Diabetologia 2006, 49:748-754.

17. Brøns C, Jensen CB, Storgaard H, Hiscock NJ, White A, Appel JS, Jacobsen S, Nilsson E, Larsen CM, Astrup A, Quistorff B, Vaag A: Impact of short-term high-fat feeding on glucose and insulin metabolism in young healthy men. J Physiol 2009, 587:2387-2397.

18. Clore JN, Helm ST, Blackard WG: Loss of hepatic autoregulation after carbohydrate overfeeding in normal man. J Clin Invest 1995, 96:1967-1972.

19. Fach D, Minehira K, Schwarz JM, Periasami R, Seongsu P, Tappy L: Effect of fructose overfeeding and fish oil administration on hepatic de novo lipogenesis and insulin sensitivity in healthy men. Diabetes 2005, 54:1907-1913.

20. Sadur CN, Yost TJ, Eckel RH: Fat feeding decreases insulin responsiveness of adipose tissue lipoprotein lipase. Metabolism 1984, 33:1043-1047.

21. Boden G, Chen X, Rosner R, Barton M: Effects of a 48-h fat infusion on insulin secretion and glucose utilization. Diabetes 1995, 44: 1239-1242.

22. Boden G: Role of fatty acids in the pathogenesis of insulin resistance and NIDDM. Diabetes 1997, 46:3-10.

23. Marshall JA, Hamman RF, Baxter J: High-fat, low-carbohydrate diet and the etiology of non-insul independent diabetes mellitus: the San Luis Valley Diabetes Study. Am J Epidemiol I99I, I34:590-603.

24. Pereira MA, Kartashov Al, Ebbeling CB, Van Horn L, Slattery ML, Jacobs Jr DR, Ludwig DS: Fast-food habits, weight gain, and insulin resistance (the CARDIA study): I5-year prospective analysis. Lancet 2005, 365:36-42.

25. Salmeron J, Manson JE, Stampfer MJ, Colditz GA, Wing AL, Willett WC: Dietary fiber, glycemic load, and risk of non-insulindependent diabetes mellitus in women. JAMA 1997, 277:472-477.

26. Schulze MB, Manson JE, Ludwig DS, Colditz GA, Stampfer MJ, Willett WC, Hu FB: Sugar-sweetened beverages, weight gain, and incidence of type 2 diabetes in young and middle-aged women. JAMA 2004, 292:927-934.

27. Shulman GI: Cellular mechanisms of insulin resistance in humans. Am J Cardiol 1999, 84:3J-I0].

28. Kahn BB, Flier JS: Obesity and insulin resistance. J Clin Invest 2000, I 06:473-48I.

29. Pessin JE, Saltiel AR: Signaling pathways in insulin action: molecular targets of insulin resistance. J Clin Invest 2000, 106:165-169.

30. Qiao L, Goldberg JL, Russell JC, Sun XJ: Identification of enhanced serine kinase activity in insulin resistance. J Biol Chem 1999, 274: $10625-10632$.

31. White MF: Insulin signaling in health and disease. Science 2003, 302: $1710-1711$.

32. Birnbaum M]: Turning down insulin signaling. J Clin Invest 200I, I 08:655-659.

33. Um SH, Frogerio F, Watanabe M, Picard F, Joaquin M, Sticker M, Fumagalli S, Allegrini PR, Kozma SC, Auwerx J, Thomas G: Absence of S6KI protects against age- and diet-induced obesity while enhancing insulin sensitivity. Nature 2004, 43 I:200-205.

34. Patti M-E, Kahn BB: Nutrient sensor links obesity with diabetes risk. Nat Meal 2004, 10:1049-1050.

35. Aguirre V, Werner ED, Giraud J, Lee YH, Shoelson SE, White MF: Phosphorylation of Ser307 in insulin receptor substrate-I blocks interactions with the insulin receptor and inhibits insulin action. | Biol Chem 2002, 277: | 53 |- I537.

36. Qiao L, Zhande R, Jetton TL, Zhou G, Sun XJ: In vivo phosphorylation of insulin receptor substrate $I$ at serine 789 by a novel serine kinase in insulin-resistant rodents. J Biol Chem 2002, 277:26530-26539.

37. LeRoith D, Zick $Y$ : Recent advances in our understanding of insulin action and insulin resistance. Diabetes Care 200I, 24:588-597.

38. Burnett PE, Barrow RK, Cohen NA, Snyder SH, Sabatini DM: RAFF I phosphorylation of the translational regulators p70S6 kinase and 4E-BP I. Proc Natl Acad Sci USA 1998, 95:|432-|437.
39. Hara K, Yonezawa K, Kozlowski MT, Sugimoto T, Andrabi K, Weng OP, Kasuga M, Nishimoto I, Avruch J: Regulation of elF4E BPI phosphorylation by mTOR. J Biol Chem I997, 272:26457-26463.

40. Isotani S, Hara K, Tokunaga C, Inoue H, Avruch J, Yonezawa K: Immunopurified mammalian target of rapamycin phosphorylates and activates p7056 kinase [alpha] in vitro. J Biol Chem 1999, 274:34493-34498.

4I. Hinault C, Mothe-Satney I, Gautier N, Lawrence JC Jr, Van Obberghen E: Amino acids and leucine allow insulin activation of the PKB/mTOR pathway in normal adipocytes treated with wortmannin and in adipocytes from $\mathrm{db} / \mathrm{db}$ mice. FASEB | 2004, I 8: 1894-1896.

42. Pham P-TT, Heydrick SJ, Fox HL, Kimball SR, Jefferson LS Jr, Lynch CJ: Assessment of cell-signaling pathways in the regulation of mammalian target of rapamycin ( $m$ TOR) by amino acids in rat adipocytes. J Cell Biochem 2000, 79:427-44I.

43. Giorgino F, Pedrini MT, Matera L, Smith RJ: Specific Increase in p85a Expression in Response to Dexamethasone is Associated with Inhibition of Insulin-like Growth Factor-I Stimulated Phosphatidylinositol 3-kinase Activity in Cultured Muscle Cells. J Biol Chem 1997, 272:7455-7463.

44. Ueki K, Fruman DA, Brachmann SM, Tseng YH, Cantley LC, Kahn CR: Molecular balance between the regulatory and catalytic subunits of phosphoinositide 3-kinase regulates cell signaling and survival. Mol Cell Biol 2002, 22:965-977.

45. Shepherd PR, Withers DJ, Siddle K: Phosphoinositide 3-kinase: The key switch mechanism in insulin signaling. Biochem $\mathrm{J} 1998$, 333:47|-490.

46. Terauchi $Y$, Tsuji $Y$, Satoh S, Minoura H, Murakami K, Okuno A, Inukai K, Asano T, Kaburagi Y, Ueki K, Nakajima H, Hanafusa T, Matsuzawa Y, Sekihara H, Yin Y, Barrett JC, Oda H, Ishikawa T, Akanuma Y, Komuro I, Suzuki M, Yamamura K-I, Kodama T, Suzuki H, Koyasu S, Aizawa S, Tobe K, Fukui Y, Yazaki Y, Kadowaki T: Increased insulin sensitivity and hypoglycaemia in Mice lacking the p85 $\alpha$ subunit of phosphoinositide 3-kinase. Nature Genetics 1999 , 2I:230-235.

47. Ueki K, Algenstaedt P, Mauvais-Jarvis F, Kahn CR: Positive and negative regulation of phosphoinositide 3-kinase-dependent signaling pathways by three different gene products of the p $85 \alpha$ regulatory subunit. Mol Cell Biol 2000, 20:8035-8046.

48. Mauvais-Jarvis F, Ueki K, Fruman DA, Hirshman MF, Sakamoto K, Goodyear LJ, lannacone M, Accili D, Cantley LC, Kahn CR: Reduced expression of the murine p85 $\alpha$ subunit of phosphoinositide 3-kinase improves insulin signaling and ameliorates diabetes. I Clin Invest 2002, 109: 141-149.

49. Ueki K, Fruman DA, Uballe CM, Fasshauer M, Klein J, Asano T, Cantley LC, Kahn CR: Positive and negative roles of $\mathrm{p} 85 \alpha$ and $\mathrm{p} 85 \beta$ regulatory subunits of phosphoinositide 3-kinase in insulin signaling. J Biol Chem 2003, 278:48453-48466.

50. Steele R: Influences of glucose loading and of injected insulin on hepatic glucose output. Ann N Y Acad Sci 1959, 82:420-30.

5I. Finegood DT, Bergman RN, Vranic M: Estimation of endogenous glucose production during hyperinsulinemic-euglycemic glucose clamps. Comparison of unlabeled and labeled exogenous glucose infusates. Diabetes 1987, 36:9|4-24.

52. Barbour LA, Shao J, Qiao L, Leitner W, Anderson M, Friedman JE, Draznin B: Human placental growth hormone increases expression of p85 regulatory unit of phosphatidylinositol 3kinase and triggers severe insulin resistance in skeletal muscle. Endocrinol 2004, | 45: I | 44- I I 50.

53. Khamzina L, Veilleux A, Bergeron S, Marette A: Increased activation of the mammalian target of rapamycin pathway in liver and skeletal muscle of obese rats: possible involvement in obesity-linked insulin resistance. Endocrinol 2005, | 46:1473-148|.

54. Trembley F, Gagnon A, Veilleux A, Sorisky A, Marette A: Activation of the mammalian target of rapamycin pathway acutely inhibits insulin signaling to Akt and glucose transport in 3T3LI and human adipocytes. Endocrinol 2005, I46:1328-I337.

55. Phillips DI, Caddy S, Fielding KN, Frayn KN, Borthwick AC, Taylor R: Intramuscular triglyceride and muscle insulin sensitivity: evidence for a relationship in nondiabetic subjects. Metabolism 1996, 45:947-950.

56. Sinha R, Dufour S, Petersen KF, LeBon V, Enoksson S, Ma YZ, Savoye M, Rothman DL, Shulman GI, Caprio S: Assessment of skeletal muscle triglyceride content by IH nuclear magnetic resonance spectroscopy in lean and obese adolescents: relation- 
ships to insulin sensitivity, total body fat, and central adiposity. Diabetes 2002, 5 I: 1022-1027.

57. Pan DA, Lillioja S, Kriketos AD, Milner MR, Baur LA, Bogardus C, Jenkins $A B$, Storlien LH: Skeletal muscle triglyceride levels are inversely related to insulin action. Diabetes 1997, 46:983-988.

58. Goodpaster BH, He J, Watkins S, Kelley DE: Skeletal muscle lipid content and insulin resistance: evidence for a paradox in endurance-trained athletes. J Clin Endocrinol Metab 200I, 86:5755-576.

59. Nadeau KJ, Ehlers LB, Aguirre LE, Reusch JE, Draznin B: Discordance between intramuscular triglyceride and insulin sensitivity in skeletal muscle of Zucker diabetic rats after treatment with fenofibrate and rosiglitazone. Diabetes Obes Metab 2007, 9(5):7|4-23.

60. Ochiai M, Matsuo T: Effects of Short-Term Dietary Change from High-Carbohydrate Diet to High-Fat Diet on Storage, Utilization, and Fatty Acid Composition of Rat Muscle Triglyceride during Swimming Exercise. J Clin Biochem Nutr 2009, 44(2): $168-177$.

6I. Lee JS, Pinnamaneni SK, Eo SJ, Cho IH, Pyo JH, Kim CK, Sinclair AJ, Febbraio MA, Watt MJ: Saturated, but not $n-6$ polyunsaturated, fatty acids induce insulin resistance: role of intramuscular accumulation of lipid metabolites. I Appl Physiol 2006, 100(5): 1467-74.

Publish with Bio Med Central and every scientist can read your work free of charge

"BioMed Central will be the most significant development for disseminating the results of biomedical research in our lifetime. "

Sir Paul Nurse, Cancer Research UK

Your research papers will be:

- available free of charge to the entire biomedical community

- peer reviewed and published immediately upon acceptance

- cited in PubMed and archived on PubMed Central

- yours - you keep the copyright

Submit your manuscript here:

http://www.biomedcentral.com/info/publishing_adv.asp
BiolMedcentral 